\title{
Effect of a two-step solution heat treatment on the microstructure and mechanical properties of 332 aluminium silicon cast alloy
}

\begin{abstract}
This paper investigated the effect of a two-step solution heat treatment on the mechanical properties and silicon-rich phase of 332 aluminium alloy. Traditional single-step T6 solution treatment $\left(495{ }^{\circ} \mathrm{C} / 6 \mathrm{~h}\right)$ increased the hardness value of the alloy by $5.96 \%$, increased the tensile strength by $20.42 \%$ and reduced the elongation by $3.97 \%$. Two-step solution treatment of the alloy $\left(495{ }^{\circ} \mathrm{C} / 2 \mathrm{~h}\right.$ followed by $515{ }^{\circ} \mathrm{C} / 4 \mathrm{~h}$ ) increased the hardness value by $6.64 \%$, increased the tensile strength by $16.01 \%$, and reduced the elongation by $4.67 \%$ compared to the as-cast samples. Both solution treatments were followed by hot water quenching (75ï 90 ${ }^{\circ} \mathrm{C}$ ) and artificial aging at $250{ }^{\circ} \mathrm{C}$ for $4 \mathrm{~h}$. The difference in mechanical properties after heat treatment can be linked to the refinement and the spheroidisation of the silicon-rich phase in the alloy.
\end{abstract}

Keyword: Heat treatment; Mechanical properties; Aluminum; Aluminum alloys 